\title{
sciendo
}

CIVIL AND ENVIRONMENTAL ENGINEERING REPORTS

E-ISSN 2450-8594

CEER 2021; 31 (2): 0117-0137

DOI: 10.2478/ceer-2021-0023

Original Research Article

\section{ASSESSMENT OF SEISMIC BEARING CAPACITY OF A STRIP FOOTING RESTING ON REINFORCED EARTH BED USING PSEUDO-STATIC ANALYSIS}

\author{
Sagar JAISWAL ${ }^{1}$, Vinay Bhushan CHAUHAN ${ }^{2}$ \\ ${ }^{1}$ Department of Civil Engineering, Madan Mohan Malaviya University of Technology, \\ Gorakhpur, India \\ ${ }^{2}$ Department of Civil Engineering, Madan Mohan Malaviya University of Technology, \\ Gorakhpur, India
}

\begin{abstract}
The use of geosynthetic reinforcement to enhance the ultimate load-bearing capacity and reduce the anticipated settlement of the shallow foundation has gained sufficient attention in the geotechnical field. The improved performance of the shallow foundation is achieved by providing one or more layers of geosynthetics below the foundation. The full wraparound technique proved to be efficient for the confinement of soil mass and reduction in settlement of foundation however lacks the literature to ascertain the performances of such footing under dynamic loading. In view of the above, the present study examines the effect of geosynthetic layers having a finite length with full wraparound ends as a reinforcement layer, placed horizontally at a suitable depth below the foundation using the finite element modeling (FEM) and evaluates the ultimate loadbearing capacity of a strip footing resting on loose and dense coarse-grained earth beds under seismic loading and further compared to those of footing resting on unreinforced earth bed. Moreover, the effect of horizontal seismic acceleration coefficient $\left(\mathrm{k}_{\mathrm{h}}\right)$ on the ultimate load-bearing capacity has been investigated by varying $\mathrm{k}_{\mathrm{h}}$ from 0.1 to 0.6 at an interval of 0.1 , for both reinforced and unreinforced earth bed having loose and dense soil strata. Furthermore, this study demonstrates that by adopting the new practice of using the
\end{abstract}

\footnotetext{
${ }^{2}$ Corresponding author: Assistant Professor, Department of Civil Engineering, Madan Mohan Malaviya University of Technology, Gorakhpur, India, e-mail: vbcce@mmmut.ac.in
} 
geosynthetic reinforcement with the full wraparound ends in foundations, it is possible to support relatively heavier structures under static as well as dynamic loading without allowing large footing settlements. From the outcomes of the present study, it is noted that the ultimate load-bearing capacity of footing resting on loose and dense sand bed found to be improved by $60 \%$ and $18 \%$ for soils having friction angle of $25^{\circ}$ and $40^{\circ}$, respectively compared to respective unreinforced earth beds under static condition.

Keywords: reinforced earth bed, bearing capacity, strip footing, finite element method, pseudo-static analysis

\section{INTRODUCTION}

Soil reinforcement is a method to enhance the stability of the overall structure (e.g., bridge abutment, mechanically stabilized earth walls, etc.) by adopting the practices of the high tensile member below the foundation in the form of geosynthetics [27, 34]. Over the past few decades, there are several innovative ground modification techniques such as reinforcing soils using geosynthetics that have been developed and widely adopted in the field. The construction of a reinforced earth bed to support a shallow foundation has significant potential as an inexpensive alternative to traditional ground modification methods. Through the various available literature, it is noted that the various materials such as metal strips [10, 12], rope fibers [2], and geogrid [11] have been used for reinforcing the earth bed to demonstrate that the inclusion of reinforcing material in the foundation bed can readily improve the ultimate load-bearing capacity and the settlement characteristics of the foundation soil. However, out of many alternatives to reinforce the earth bed, reinforcement using geosynthetics material is found best due to its cost-effectiveness, and speedy construction. In this technique, reinforcing material having a definite length is placed in one or many layers at a predetermined gap between successive reinforcing layer beneath the footing to enhance the bearing capacity of the footing.

From the findings of the past investigation carried out using numerous experimental and numerical studies, it is found that the ultimate load-bearing capacity of a shallow footing resting on sand reinforced with layers of geogrid and subjected to a centric vertical load can be enhanced significantly $[1,2,4,11,12$, $28,39]$. Furthermore, these studies reported that the performance of the footing can be improved by the introduction of reinforcement materials only when the reinforcement is placed within a certified depth beyond which no significant improvement will occur in the stiffness characteristics of the soil. Khing et al. [21], and Aria et al. [3] suggested that reinforcement material used as a single or multiple layer (3 to 4 layers) of geosynthetics, rested horizontally within the earth bed having the length of the reinforcing layers 4 to 6 times the footing width, provides sufficient stiffness and confinement to the underlying soil. In a study, 
Bera et al. [6], reported that the optimum length of reinforcement is 5 to 7 times the width of the footing for a square footing on reinforced pond ash.

However, sometimes due to the presence of nearby structures on the site or another property line, does not permit the provision of the required length of the reinforcement. To provide a solution to such problems, Kazi et al. [17-20] and Shukla [33] have proposed the reinforcing layer with wraparound ends, which requires a much lower width of land for the placement of the reinforcing layer with an additional increase in the load-bearing capacity, compared with reinforcement layers placed horizontally without wraparound ends within the same sand bed system. Not only the material requirement, but the expansion of land excavation along the length of reinforcement also may not be possible due to the unavailability of land space or due to the presence of a property line or any existing structure nearby, which may limit the placement of adequate length of the reinforcement.

Such need-based demand raised the concept of full wraparound ends of geosynthetics reinforcement is presented in this study to improve the bearing capacity of cohesionless foundation soil below strip footing to avoid deep excavation and provide savings in the land space to form a reinforced earth bed system, which helps in minimizing the overall cost of the project.

The available literature for the reinforcement of cohesionless soil mass has focused only on the static loading and unfortunately, only a few studies are available on the dynamic response of reinforced soil mass. The reason for this may be the unavailability of suitable instrumentation for analyzing the internal stress and strain while performing the seismic analysis in the laboratory. Numerical modeling is a fast, better, and accurate approach to investigate the model under static and dynamic conditions in a very short period. Kumar and Chakraborty [24], recently studied the seismic bearing capacity of rough strip footing resting on geogrid reinforced earth bed by using lower bound limit theorem and demonstrated that inserting a single layer of reinforcement beneath the footing can improve the ultimate load-bearing capacity of weak soil strata.

The seismic forces induced due to earthquake events can affect the bearing capacity of the foundation soil which may eventually cause structural failure. In the present study, an attempt has been made to study the load-settlement response of a strip footing resting on a reinforced earth bed with full wraparound ends of the geosynthetics under the action of horizontal seismic forces.

Fig. 1 shows the footing resting over the reinforced with a detailed layout of the placement of geosynthetic layers considered in the study, where B, b, and d are footing width, length of the reinforcement layer, and vertical length of the full wraparound end respectively. Moreover, 1 and $u$ represent the lap length and the burial depth of the topmost layer from the bottom of the footing and $h$ is the vertical spacing between the successive reinforcement layers. From the literature, 
it had been noted that the magnitude of the load-bearing capacity for a given strip foundation resting over the reinforcement earth bed with geogrid having full wraparound ends is the function of the number of parameters namely the normalized length of reinforcement $(\mathrm{b} / \mathrm{B})$, the normalized vertical length of wraparound ends $(\mathrm{d} / \mathrm{B})$, normalized lap length $(1 / \mathrm{B})$, normalized burial depth of the first layer $(\mathrm{u} / \mathrm{B})$ and the normalized vertical spacing $(\mathrm{h} / \mathrm{B})$. Based on the literature review, it is found that the researchers recommended the range of the above-discussed parameters for efficient utilization of reinforcement technique to be applied on the footing under static loading:

$\mathrm{b} / \mathrm{B}=4$ [17]; $\mathrm{h} / \mathrm{B}=0.2-0.4$ [28]; $\mathrm{d} / \mathrm{B}=0.2$ [19]; $\mathrm{u} / \mathrm{B}=0.3$ [20, 28].

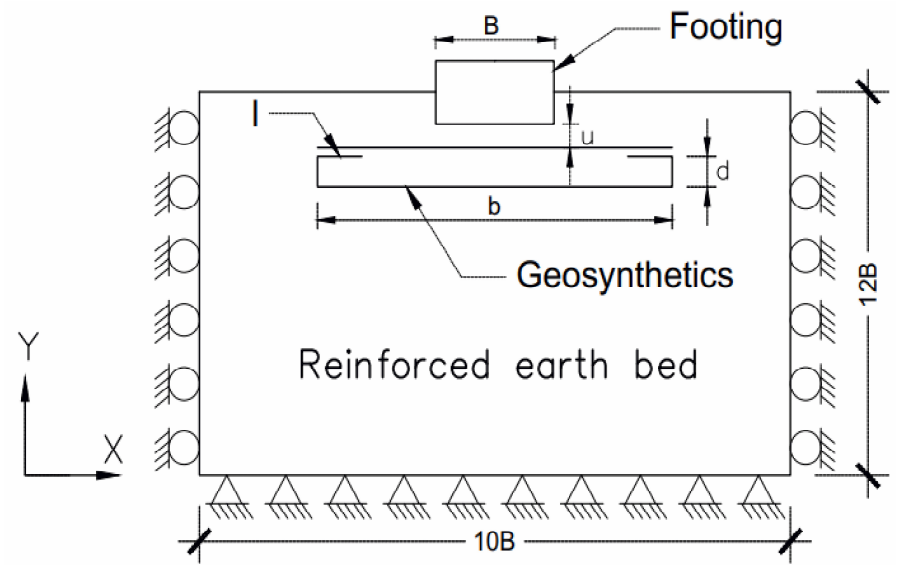

Fig. 1. Geometry of full wraparound ends of geosynthetics and boundary conditions

In practical situations, after placement of the first layer, the soil is compacted and then the second layer is introduced and again compaction is done, which helps in attaining dense strata of soil foundation. Sometimes due to negligence, it is also possible that the stratum could not be compacted efficiently resulting in loose soil strata. Given the above, a comprehensive numerical study based on the finite element method has been carried out to evaluate the load-bearing capacity of a shallow foundation under the seismic condition for a wide spectrum of friction angles, $\phi$ of $25^{\circ}$ and $40^{\circ}$, as the difference between the angle of internal friction of given sand in the densest and the loosest state may be as high as $15^{\circ}$ [37].

Furthermore, to investigate the effects of horizontal seismic acceleration coefficient, $\mathrm{k}_{\mathrm{h}}$, on the bearing capacity of the footing resting on loose and dense reinforced soil, numerical investigations have been carried out to investigate the load-settlement response of the footing, under static loading $\left(\mathrm{k}_{\mathrm{h}}=0\right)$ and various seismic loading corresponds to the horizontal seismic acceleration coefficient $\left(\mathrm{k}_{\mathrm{h}}\right)$ ranging from 0.1 to 0.6 at an interval of 0.1 . The pseudo-static analysis is adopted in the present study by considering only the horizontal seismic acceleration 
coefficient $\left(\mathrm{k}_{\mathrm{h}}\right)$ [22]. Moreover, the load versus settlement curve for the footing resting on a reinforced earth bed is studied and compared with the unreinforced one.

\section{NUMERICAL MODELING}

A two-dimensional finite element program, Optum G2, has been used to model a strip footing under vertical loading and seismic horizontal acceleration, resting on a sand bed reinforced with full wraparound ends of geosynthetics reinforcement [29]. The reinforcement configurations as shown in Fig. 1, considered in this study are normalized with the footing width $(2 \mathrm{~m})$ such as $\mathrm{b} / \mathrm{B}=4, \mathrm{~h} / \mathrm{B}=0.2, \mathrm{~d} / \mathrm{B}=0.2$, $\mathrm{u} / \mathrm{B}=0.3$. The reinforcement layers are modeled using a structural geogrid element with elastic stiffness, EA (where $\mathrm{E}=$ Young's modulus and $\mathrm{A}=$ area of the crosssection of geosynthetics) (Table 1).

Table 1. Material properties used in the present analysis

\begin{tabular}{llll}
\hline Parameter & Loose soil & Dense soil & Geosynthetics \\
\hline${\text { Friction angle, } \phi\left(^{\circ}\right)^{\mathrm{a}}}^{\mathrm{a}}$ & $25^{\circ}$ & $40^{\circ}$ & - \\
${\text { Dry unit weight, } \gamma_{\mathrm{d}}\left(\mathrm{kN} / \mathrm{m}^{3}\right)^{\text {a }}}$ & 15 & 17.65 & - \\
${\text { Bulk modulus, } \mathrm{K}(\mathrm{MPa})^{\mathrm{a}}}^{\mathrm{a}}$ & 27 & 100 & - \\
${\text { Shear modulus, } \mathrm{G}(\mathrm{MPa})^{\mathrm{a}}}$ & 9 & 38 & - \\
Cohesion, c $(\mathrm{kPa})$ & 0 & 0 & - \\
Axial stiffness, EA $(\mathrm{kN} / \mathrm{m})^{\mathrm{b}}$ & - & - & 1000
\end{tabular}

${ }^{\mathrm{a}}$ (Chugh and Labuz [9]); ${ }^{\mathrm{b}}$ (Benmebarek et al. [5])

As shown in Fig. 1, a rigid strip footing (concrete) is considered having a width (B) of $2 \mathrm{~m}$, resting on the surface of the reinforcement earth bed. The sand bed is assumed to follow the Mohr-Coulomb failure criterion, which requires the parameters namely, the friction angle $(\phi)$, shear modulus $(\mathrm{G})$, and bulk modulus (K) (as shown in Table 1) to model the soil behavior $[5,9]$. Moreover, the interaction between the geosynthetic material and the surrounding soil was simulated by interface elements located at the common surface between soil and reinforcement surface, having an interface parameter, namely strength reduction factor $\mathrm{R}_{\text {int, }}$ which is assumed to be $2 / 3[13,18]$.

For the present numerical model, six-node triangular elements with a three-point Gaussian integration rule are preferred and used in the present study. A plane strain condition is considered in the analysis, in which the strain associated with the third direction (perpendicular to the $\mathrm{x}-\mathrm{y}$ plane) is zero, which provides numerical advantages to treat the problem as two dimensional [31]. The boundary conditions of the model are applied in a manner such that the movement of vertical 
boundaries are constrained in the horizontal direction, while the bottom horizontal boundary was constrained to move vertically as well as laterally. To minimize the effects of the boundary condition on the response of the strip footing under vertical load, the boundaries of the model is considered such that, vertical is located at $5 \mathrm{~B}$ in both directions from the central vertical line of the footing and the bottom horizontal end is located at 12B from the footing, as shown in Fig. 1. The boundary conditions adopted were far away, such that the plastic movement and the failure plane obtained in the analysis were not being intercepted.

To obtain accurate results from the numerical model, the selection of an appropriate number of elements in the mesh is the primary essential requirement in numerical simulation $[16,30]$. A sensitivity analysis was performed by varying the number of total elements in the mesh from 1000 to 10000 and it is found that 6000 elements were good enough for the considered mesh in the present study based on an observed outcome by varying the number of elements in the mesh (Fig. 2) [14, 15, 34-36].

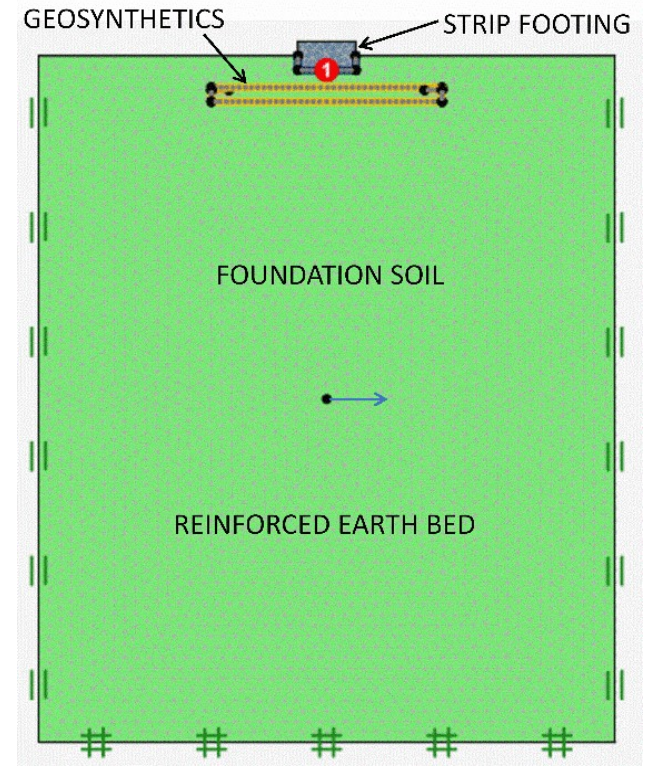

Fig. 2. Finite element model considered for strip footing resting on foundation soil reinforced with full wraparound ends of geosynthetics

An incremental vertical uniformly distributed surcharge on the footing and a seismic horizontal acceleration on the body of the considered mesh is applied to investigate the behavior of footing under the effect of seismic loading. Based on the above simulations, the load-settlement response has been plotted by considering various parameters of the geosynthetics reinforcement using the full wraparound technique discussed in the previous section. 


\section{VALIDATION OF THE NUMERICAL MODEL}

To validate the numerical model used in the present study, a strip footing resting on the unreinforced earth bed is analyzed using the Mohr-Coulomb model (c- $\phi$ soil) and the values of the bearing capacity factor due to the cohesion component of soil $\left(\mathrm{N}_{\mathrm{c}}\right)$ and bearing capacity factor from the component of unit weight $\left(\mathrm{N}_{\gamma}\right)$ are obtained by lower bound limit analysis using FEM and compared with values obtained by various researchers and discussed below.

The magnitude of the collapse load $\left(\mathrm{q}_{\mathrm{u}}\right)$ per unit length of the footing caused by the cohesion component of soil can be determined with the use of the bearing capacity expression:

$$
q_{u}=c N_{c}+0.5 \gamma B N_{\gamma}
$$

where $\mathrm{N}_{\mathrm{c}}$ and $\mathrm{N}_{\gamma}$ are the bearing capacity factor due to the cohesion component of soil unit weight respectively, $\mathrm{q}_{\mathrm{u}}, \mathrm{c}$, and $\gamma$ are the ultimate load-bearing capacity, cohesion, and unit weight of the earth bed respectively. The values of $\mathrm{N}_{\mathrm{c}}$ and $\mathrm{N}_{\gamma}$ were calculated by a back-calculation using Terzaghi's bearing capacity equation for a surface strip footing by applying the superposition principle (Eq. 3.1) and compared with the results obtained by various researchers and shown in Figs. 3 and 4 [37].

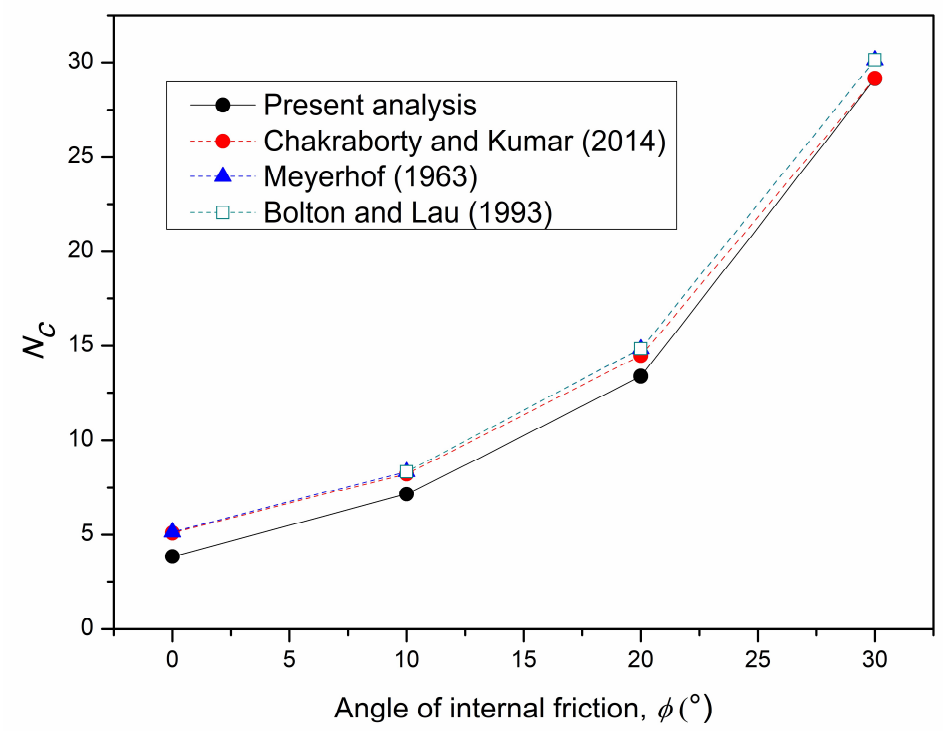

Fig. 3. Comparison of bearing capacity factor, $N_{c}$ obtained in the present analysis with various available literature for unreinforced earth bed with the angle of internal friction 


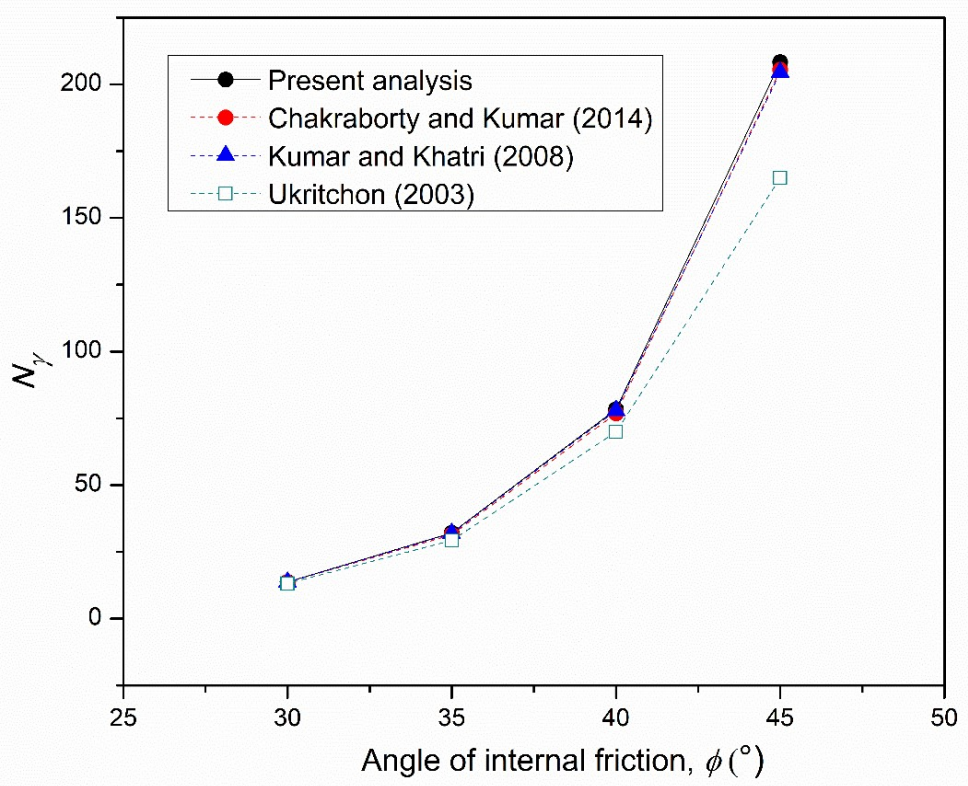

Fig. 4. Comparison of bearing capacity factor, $\mathrm{N}_{\gamma}$ obtained in present analysis with various available literature for unreinforced earth bed with the angle of internal friction

$(\phi)$

The values of $\mathrm{N}_{\mathrm{c}}$ and $\mathrm{N}_{\gamma}$ increase continuously with an increase in the value of $\phi$. The values of bearing capacity factor $\mathrm{N}_{\mathrm{c}}$ were compared with the results of Meyerhof [26] obtained using the limit equilibrium analysis, Bolton, and Lau [7] achieved by the method of the stress characteristics approaches, and Chakraborty and Kumar [8] using the lower bound limit analysis with finite elements and linear programming (as shown in Fig. 3). The value $\mathrm{N}_{\mathrm{c}}$ obtained from the present analysis is marginally lower than the values reported by the researchers, however, with the increase in the value of $\phi$, the deviation in the results converges and coincides with the value reported by the lower bound limit analysis for $\phi=30^{\circ}$.

Similarly, the values of $\mathrm{N}_{\gamma}$ were compared with the results of Kumar and Khatri [23] obtained by linear programming, and Ukritchon et al. [38] and Chakraborty and Kumar [8] obtained with lower bound limit analysis (as shown in Fig. 4). It can be seen that for different values of the angle of internal friction of soil $(\phi)$, the results obtained from the present analysis are quite favorable with the exiting reckoning results of Kumar and Khatri [23], and Chakraborty and Kumar [8]. Moreover, the current numerical model is well validated with the results reported by Saha and Ghosh [32] for seismic bearing capacity factor $\left(\mathrm{N}_{\gamma \mathrm{e}}\right)$ obtained for $\phi=$ $20^{\circ}$ at $\mathrm{k}_{\mathrm{h}}=0.1,0.15$ and 0.2 with a variation of around $3 \%$ for the first two cases and $8 \%$ for the latter one. 
Concerning the above, the result obtained in the present analysis are quite favorable with most of the reported results, and this model is found to be a wellvalidated model to use for further analysis.

\section{RESULTS AND DISCUSSIONS}

This section demonstrates and discusses the findings of the study based on the numerical simulations carried out with the various geometrical configurations of geosynthetics reinforcement (i.e., $\mathrm{b} / \mathrm{B}=4, \mathrm{~h} / \mathrm{B}=0.2, \mathrm{~d} / \mathrm{B}=0.2, \mathrm{u} / \mathrm{B}=0.3$ ). Moreover, the load-settlement responses of the footing under seismic loading and vertical loading on the footing resting on the earth bed surface has been presented graphically.

In the design of any foundation, one must consider the safety against the bearing capacity failure as well as against excessive settlement of the footing. Concerning this, the load-settlement response of unreinforced and reinforced earth bed is obtained from the detailed parametric studies mentioned in the previous section and compared suitably. The primary purpose of this numerical study is to evaluate the effect of full wraparound ends of geosynthetics reinforced loose and dense earth beds, on the settlement behavior under the influence of horizontal seismic acceleration coefficient $\left(\mathrm{k}_{\mathrm{h}}\right)$.

The study on the loose and dense unreinforced earth bed is conducted in static and dynamic conditions and for better understanding, the variation of load versus normalized settlement of the footing is thus plotted and shown in Figs. 5 and 6 . For loose cohesionless soil (i.e. $\phi=25^{\circ}$ ) it is observed that the ultimate loadbearing capacity (qult) decreases with the increment in horizontal seismic acceleration coefficient $\left(\mathrm{k}_{\mathrm{h}}\right)$, and also the ground was found unstable beyond $\mathrm{k}_{\mathrm{h}}=$ 0.5 (as shown in Fig. 5). Also, it is seen that as $\mathrm{k}_{\mathrm{h}}$ changes from 0 to 0.4 , the peaks of the normalized settlement of the footing ( $/ \mathrm{B} \%$ ) changes from $10.72 \%$ to $4.07 \%$. This may be attributed to the fact that the soil with a lower friction angle may not be stable under high seismic loads and unable to support the footing up to a greater extent. Similarly, for dense cohesionless soil (i.e. $\phi=40^{\circ}$ ), it is found that the value of qult is greater than the loose one, at the same s/B \% (Fig. 6), this may be due to the closeness of the soil particles in its dense state. The $\mathrm{s} / \mathrm{B} \%$ at $\mathrm{k}_{\mathrm{h}}$ $=0$ and 0.6 was found to be $30.58 \%$ and $14.30 \%$ with the $\mathrm{qult}_{\mathrm{ult}}=2836.65 \mathrm{kPa}$ and $1835.25 \mathrm{kPa}$ respectively. For both states of the denseness of the soil mass, the value of $\mathrm{q}_{\mathrm{ult}}$ decreases as the $\mathrm{k}_{\mathrm{h}}$ amplifies beyond 0 . 


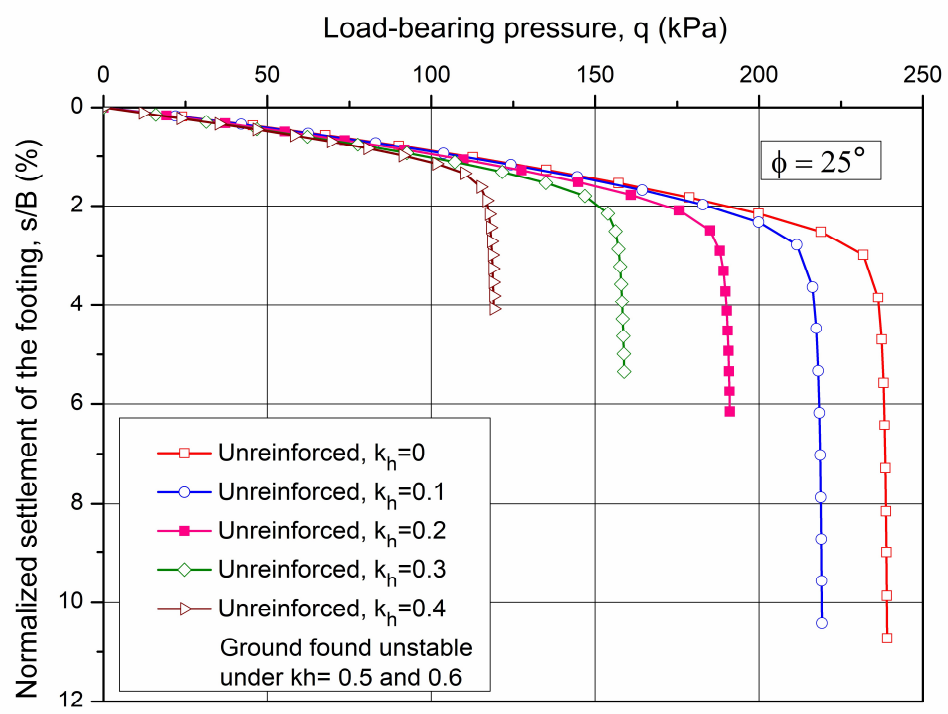

Fig. 5. Load-settlement response for strip footing resting on unreinforced earth bed with loose cohesionless soil for varying $\mathrm{k}_{\mathrm{h}}$

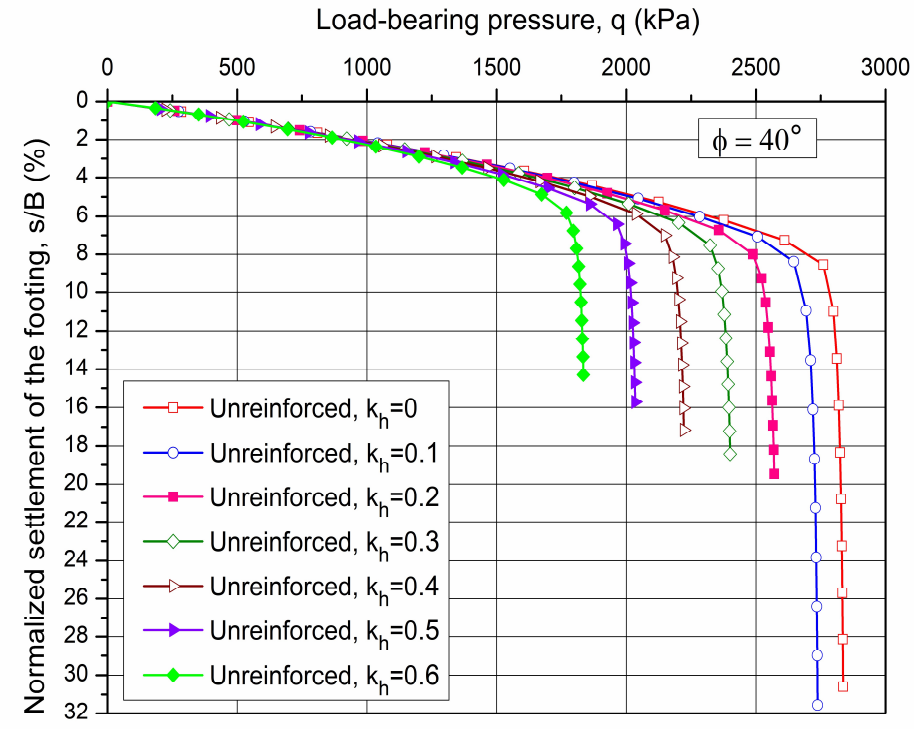

Fig. 6. Load-settlement response for strip footing resting on unreinforced earth bed with dense cohesionless soil for varying $\mathrm{k}_{\mathrm{h}}$ 


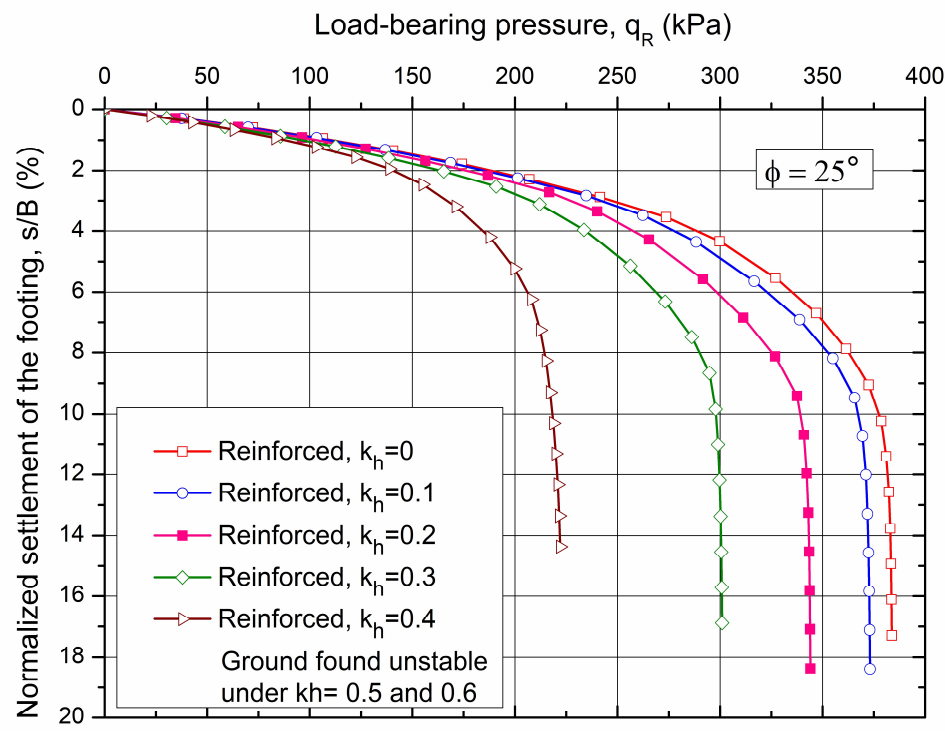

Fig. 7. Load-settlement response for strip footing resting on reinforced earth bed with loose cohesionless soil for varying $\mathrm{k}_{\mathrm{h}}$

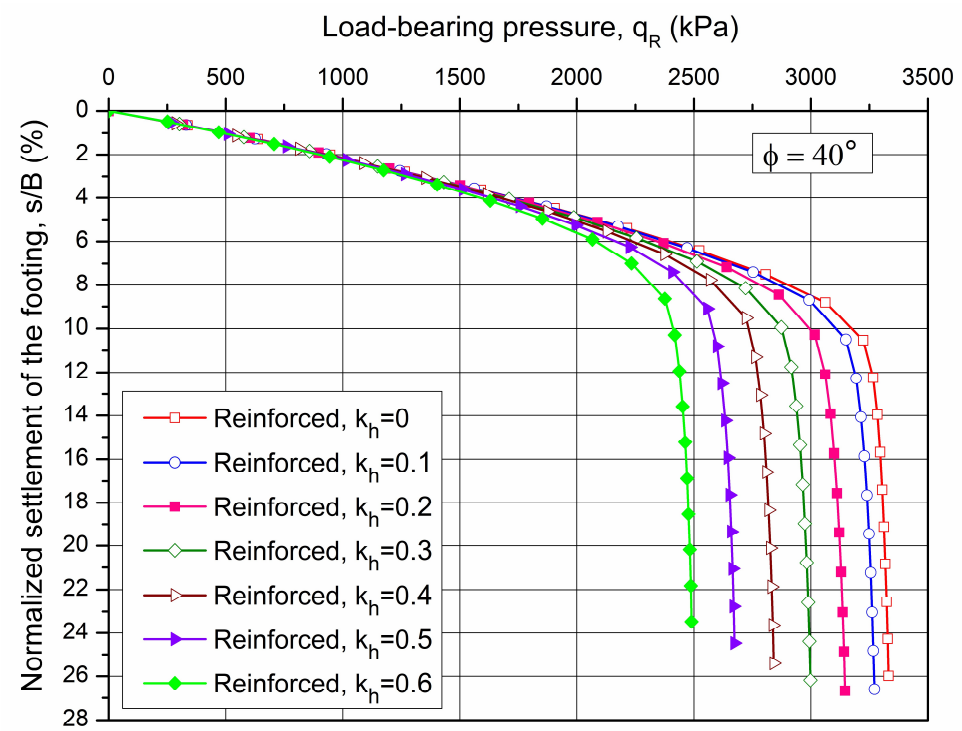

Fig. 8. Load-settlement response for strip footing resting on reinforced earth bed with dense cohesionless soil for varying $\mathrm{k}_{\mathrm{h}}$ 
A similar study resembling the above is conducted with the inclusion of geosynthetics material with full wraparound technique and the results from the numerical analysis are shown in the form of curves outlined between the loadbearing pressure $\left(\mathrm{q}_{\mathrm{R}}\right)$ and normalized settlement ratio ( $\left.\mathrm{s} / \mathrm{B} \%\right)$ for loose and dense cohesionless soil respectively, as shown in Figs. 7 and 8. It can be inferred from the obtained curves that for any corresponding s/B \%, the load-bearing pressure is higher for the reinforced earth bed than the unreinforced one. However, the improvement in the case of loose soil is found to be more significant with respect to the dense soil. The ultimate load-bearing pressure of reinforced earth bed ( $q_{\text {ult, }}$ R) at $\mathrm{k}_{\mathrm{h}}=0$ and 0.4 are found to be $383.80 \mathrm{kPa}$ and $222.14 \mathrm{kPa}$ respectively for loose soil, whereas for dense soil it is observed to be $3332.10 \mathrm{kPa}$ and 2490.10 $\mathrm{kPa}$ at $\mathrm{k}_{\mathrm{h}}=0$ and 0.6 respectively. The variation trend of load versus normalized settlement response at static conditions is found very close to the results of Adams and Collin [1] and Kazi et al. [17].

Table 2. Ultimate load-bearing capacity for unreinforced ( $\left.\mathrm{q}_{\mathrm{ult}}\right)$ and reinforced $\left(\mathrm{q}_{\mathrm{ult}} \mathrm{R}\right)$ earth bed for loose and dense cohesionless soil under varying horizontal seismic acceleration coefficient $\left(\mathrm{k}_{\mathrm{h}}\right)$

\begin{tabular}{ccccc}
\hline \multirow{2}{*}{$\mathbf{k}_{\mathbf{h}}$} & \multicolumn{2}{c}{ Loose soil } & \multicolumn{2}{c}{ Dense soil } \\
\cline { 2 - 5 } 0 & $\mathrm{q}_{\text {ult }}(\mathrm{kPa})$ & $\mathrm{q}_{\text {ult, } \mathrm{R}}(\mathrm{kPa})$ & $\mathrm{q}_{\text {ult }}(\mathrm{kPa})$ & $\mathrm{q}_{\text {ult, } \mathrm{R}}(\mathrm{kPa})$ \\
\cline { 2 - 5 } 239.09 & 383.80 & 2836.7 & 3332.1 \\
0.1 & 219.23 & 373.18 & 2737.9 & 3271.6 \\
0.2 & 191.07 & 344.10 & 2570.5 & 3145.9 \\
0.3 & 158.88 & 301.02 & 2400.6 & 2998 \\
0.4 & 119.05 & 222.14 & 2222.1 & 2840.8 \\
0.5 & - & - & 2034.3 & 2673.3 \\
0.6 & - & - & 1835.2 & 2490.1 \\
\hline
\end{tabular}

In this study, the double tangent method is used to estimate the ultimate loadbearing capacity for the case of unreinforced ( $\mathrm{q}_{\mathrm{ult}}$ ) and reinforced earth beds ( $\mathrm{q}_{\text {ult, }}$ R). The ultimate load-bearing capacity which can be supported without failure is defined as the load corresponding to the intersection of the two tangents, one at the early part of the load-settlement plot and the other at the latter part [15, 25]. A summary of the qult and qult, R so obtained for loose and dense cohesionless soil under static and varying seismic loading is presented in Table 2 . It is noticed that qult, $\mathrm{R}$ at $\mathrm{k}_{\mathrm{h}}=0$ improves by $60 \%$ and $18 \%$ for $\phi=25^{\circ}$ and $40^{\circ}$ than the qult respectively. Also, the enhancement in the qult, $\mathrm{R}$ with respect to the qult is noted for both loose and dense cohesionless soil corresponding to various horizontal 
seismic acceleration coefficient $\left(\mathrm{k}_{\mathrm{h}}\right)$. The result indicated that an increment in qult, $\mathrm{R}$ of $70 \%, 80 \%$, and $89 \%$ than qult is observed at $\mathrm{k}_{\mathrm{h}}=0.1,0.2$, and 0.3 respectively, whereas, for dense one, the noticeable improvement in qult, $\mathrm{R}$ is found at $\mathrm{k}_{\mathrm{h}}=0.5$ and 0.6 which is approximately $31.5 \%$ and $36 \%$.

The beneficial effects of reinforcement to increase the ultimate load-bearing capacity can be expressed in terms of a non-dimensional parameter called the bearing capacity ratio (BCR). The BCR can be expressed as the ratio of the ultimate load-bearing capacity of the reinforced ( $q_{\text {ult, }}$ ) and unreinforced ( $q_{\text {ult }}$ ) earth bed at the same settlement level of the foundation. The variation of bearing capacity ratio (BCR) versus horizontal seismic acceleration coefficient $\left(\mathrm{k}_{\mathrm{h}}\right)$ for footing resting on loose and dense cohesionless soil is shown in Figs. 9 and 10. From the present analysis, it is found that the BCR for footing resting on loose cohesionless soil is more than 1.6 at $\mathrm{k}_{\mathrm{h}}=0$, which is comparable to the findings of Aria et al. [3]. Furthermore, for footing resting on loose earth bed, the BCR increases from 1.61 to 1.89 with the change in $\mathrm{k}_{\mathrm{h}}$ from 0 to 0.3 , but at $\mathrm{k}_{\mathrm{h}}=0.4$ it reduces marginally and attains a value of 1.86 as shown in Fig. 9. Also, due to seismic excitation level, beyond $\mathrm{k}_{\mathrm{h}}=0.5$ the foundation soil fails abruptly with the movement of soil in the direction of applied seismic load. For footing resting on dense cohesionless soil, the improvement in BCR is linear with the horizontal seismic acceleration coefficient $\left(\mathrm{k}_{\mathrm{h}}\right)$. Initially, at $\mathrm{k}_{\mathrm{h}}=0$ the improvement of the BCR is observed 1.17 , but at $\mathrm{k}_{\mathrm{h}}=0.6$ it is found to be 1.36 . From the curve obtained in Fig. 10, it is inferred that the enhancement in BCR is more significant with the increase in seismic loading up to a certain extent.

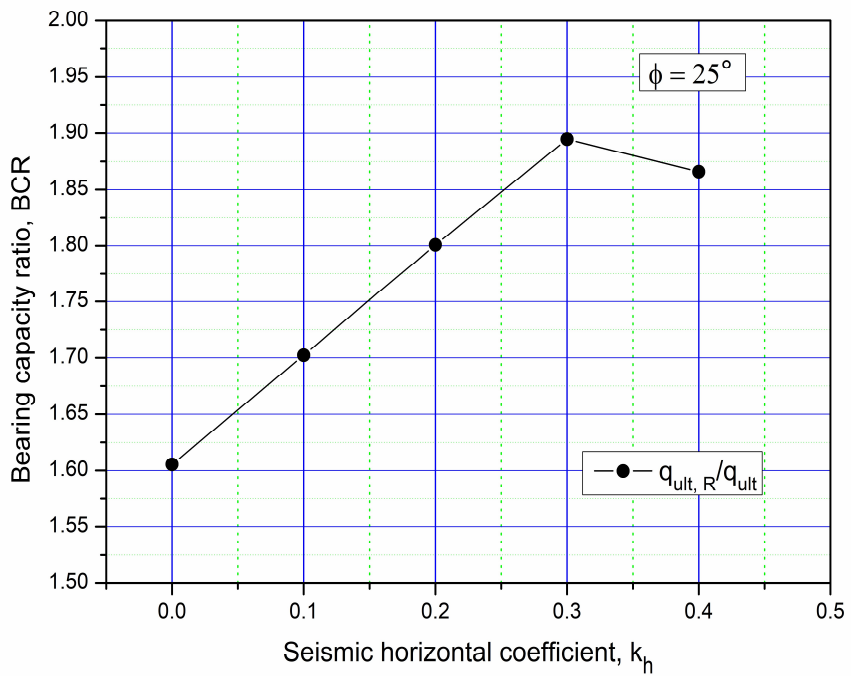

Fig. 9. Variation of bearing capacity ratio (BCR) with horizontal seismic acceleration coefficient $\left(\mathrm{k}_{\mathrm{h}}\right)$ for loose cohesionless soil 


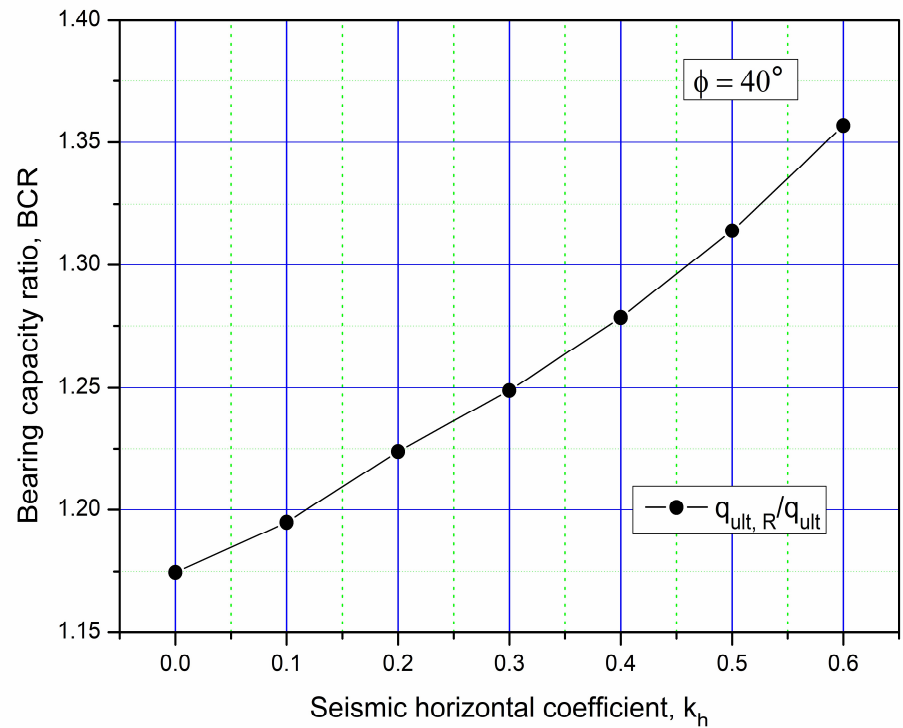

Fig. 10. Variation of bearing capacity ratio (BCR) with horizontal seismic acceleration coefficient $\left(\mathrm{k}_{\mathrm{h}}\right)$ for dense cohesionless soil

Moreover, the shear failure planes obtained in the present study are also analyzed and shown in Figs. 11 (a)-(c) and 12 (a)-(d) for loose and dense soil respectively, as the noticeable failure planes are observed for these cases of unreinforced earth bed. At static condition, it is seen that the failure pattern is symmetrical about the central vertical axis of the footing and similar to that proposed by Terzaghi [37] for the unreinforced earth bed (Figs. 11 (a) and 12(a)). An elastic wedge zone is located immediately below the footing which pushes away the soil in two symmetrical zones. For seismic conditions, the failure of the footing and soil mass is shown in Figs. 11(b)-(c) and 12 (b)-(d). A well-defined failure zone is visible in all the cases and also, the augmented failure zone develops in the direction of the applied seismic horizontal load. It can be attributed to the fact that the extent of the failure of the footing and the soil mass depends upon the magnitude of the seismic loading. 


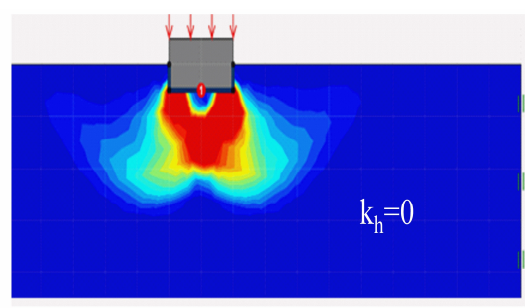

(a)

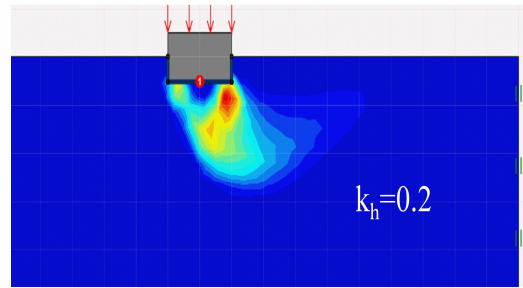

(b)

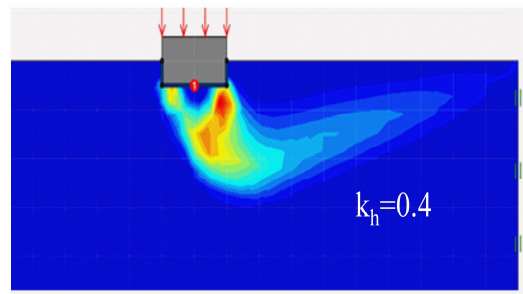

(c)

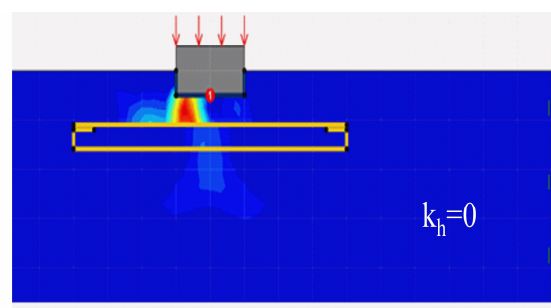

(d)

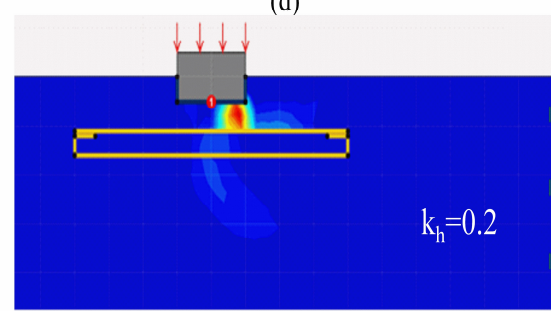

(e)

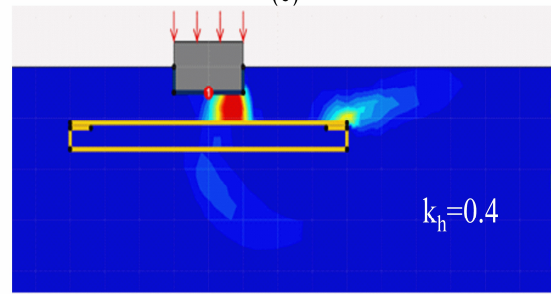

(f)

Fig. 11. Failure pattern of loose cohesionless soil for unreinforced earth bed at (a) $\mathrm{k}_{\mathrm{h}}=$ 0 ; (b) $k_{h}=0.2$ and (c) $k_{h}=0.4$; and reinforced earth bed at (d) $k_{h}=0$; (e) $k_{h}=$ 0.2 and (f) $k_{h}=0.4$ respectively

For the reinforced earth bed, the failure planes are presented in Figs. 11 (d)-(f) and $12(\mathrm{e})-(\mathrm{h})$, for $\phi=25^{\circ}$ and $40^{\circ}$, respectively. In the case of loose sand at $\mathrm{k}_{\mathrm{h}}=0$, the shear failure of the foundation soil is found to be unsymmetrical, a possible reason for this may be the rearrangement of soil particles or the load transfer mechanism on the application of surcharge, but the failure zone is restricted by the reinforcement to a limited depth (Fig. 11 (d)).

For the different cases of seismic loading, it is seen that the extents of failure surface in vertical and horizontal directions in the reinforced earth bed is less as compared to the unreinforced condition for both the cases of soil, this may be due to the presence of high tensile load-bearing member below the footing. In case of loose soil at $\mathrm{k}_{\mathrm{h}}=0.4$, for unreinforced earth bed (Fig. 11 (c)) the vicinity of shear failure is visible near the boundary, in contrast, the movement of soil in reinforced earth bed (Fig. 11 (f)) is limited under the applied seismic loading and the failure zone of foundation soil is reduced. 

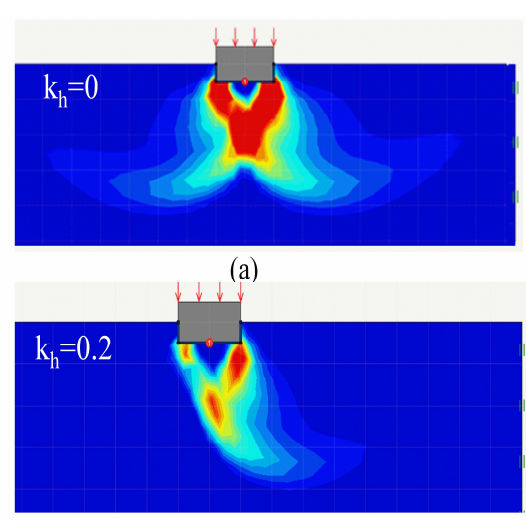

(b)

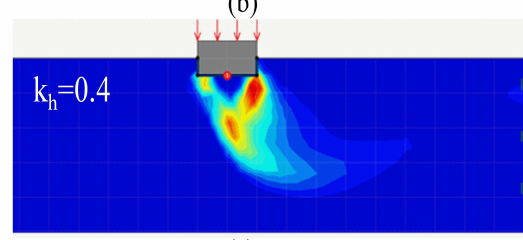

(c)

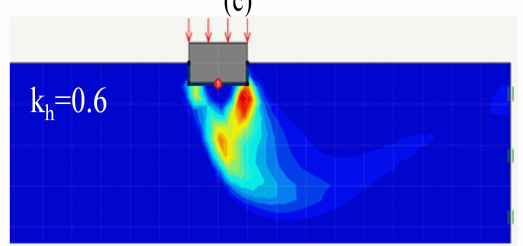

(d)

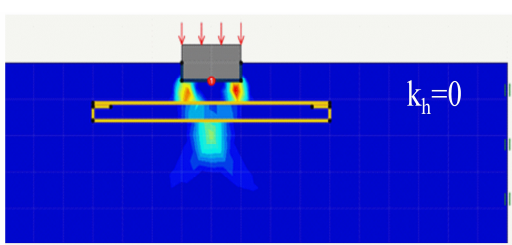

(e)

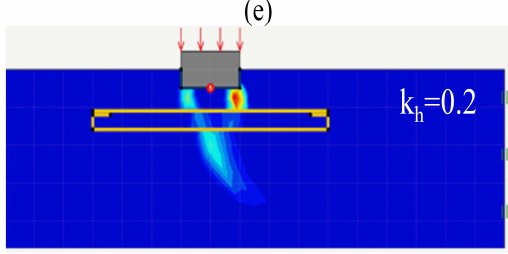

(f)

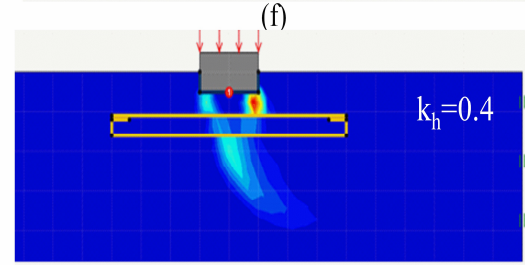

(g)

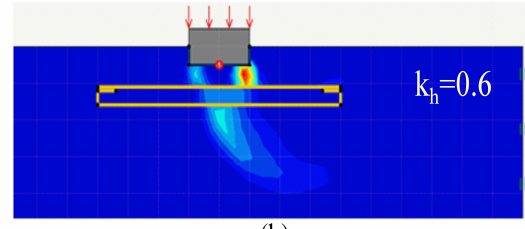

(h)

Fig. 12. Failure pattern of dense cohesionless soil for unreinforced earth bed at (a) $\mathrm{k}_{\mathrm{h}}=0$; (b) $k_{h}=0.2$; (c) $k_{h}=0.4$ and (d) $k_{h}=0.6$ and reinforced earth bed at (e) $k_{h}=0$; (f) $k_{h}=$ $0.2 ;(\mathrm{g}) \mathrm{k}_{\mathrm{h}}=0.4$ and (h) $\mathrm{k}_{\mathrm{h}}=0.6$ respectively

For the dense sand, a well-developed symmetrical failure plane at static condition is observed for the footing resting on reinforced earth bed in Fig. 12 (e), and it is also inspected that the extent of the failure region is constrained. As the amount of horizontal seismic acceleration coefficient $\left(\mathrm{k}_{\mathrm{h}}\right)$ step up, the movement of soil in the direction of applied load is observed in the failure plane (Fig. 12 (a)-(d)). Whereas the introduction of geosynthetics reinforcement has condensed the extent of the failure zone due to its tensile behavior and also the movement of soil is limited up to a certain distance, which in turn supports the foundation even at a greater horizontal acceleration.

\section{CONCLUSIONS}

A numerical study using finite element method on the behavior of strip footing supported on reinforced earth bed is presented under static and various seismic 
loading (i.e., horizontal seismic acceleration coefficients $\left(\mathrm{k}_{\mathrm{h}}\right)$ ). The study has been carried out to evaluate the behavior of strip footing resting on the loose and dense cohesionless foundation soil to investigate the effect of the ground reinforcement with full wraparound ends. As the present study is one of a novel kind of study with consideration of dynamic loading, so the findings of it can serve as a base study for similar studies using pseudo-static analysis of reinforced earth bed in the future. The obtained results can also be utilized for the validation of any similar study as well as producing an analytical method and supplying a generous database for seismic analysis. Based on the presented study, the following conclusions can be drawn:

1. The use of geosynthetics layer with full wraparound ends as reinforcement within the earth bed results in an additional increase in the ultimate load-bearing capacity $\left(\mathrm{q}_{\text {ult, }} \mathrm{R}\right)$ and delayed the failure due to settlement. Under the static condition, the maximum improvement in qult, $\mathrm{R}$ of $60 \%$, and $18 \%$ is obtained than that of qult for loose and dense cohesionless soils, respectively. The improvement in the case of loose soil is more significant, hence it can be concluded that the full wraparound technique is more beneficial for cohesionless soil having a low angle of internal friction $(\phi)$.

2. With the application of seismic loading (i.e., horizontal seismic acceleration coefficient $\left(\mathrm{k}_{\mathrm{h}}\right)$ ) on the footing resting over loose soil, the ultimate load-bearing capacity $q_{\text {ult, }} \mathrm{R}$ at $\mathrm{k}_{\mathrm{h}}=0.1$ and 0.2 is reduced by $3 \%$ and $10.2 \%$ respectively, whereas qult is reduced by $8 \%$ and $20 \%$ respectively. However, the application of geosynthetics is found more effective up to $\mathrm{k}_{\mathrm{h}}=0.3$ to improve the seismic bearing capacity of the footing.

3. The bearing capacity ratio (BCR) obtained in the present study is greater than unity for all the cases studied, which implies that the ultimate load-bearing capacity has been improved due to reinforcement even under seismic loading. For loose and dense states of soil, the BCR is obtained at 1.61 and 1.17, respectively under static loading conditions. Whereas, in the case of dynamic loading, as the $\mathrm{k}_{\mathrm{h}}$ increases, the BCR of the footing over the reinforced bed also increases. In the case of loose soil, the maximum improvement in BCR is noticed at $\mathrm{k}_{\mathrm{h}}=0.3$ i.e. 1.89 , and after this, a marginal decrease in BCR to 1.86 is observed at $k_{h}=0.4$. For dense soil, the BCR increases linearly with $k_{h}$, and a maximum improvement of 1.36 in $\mathrm{BCR}$ is noticed at $\mathrm{k}_{\mathrm{h}}=0.6$.

4. From the observation of the potential failure envelope obtained in the present study, it is perceived that the extent of the failure envelope increases for both unreinforced and reinforced soil with augmentation in $\mathrm{k}_{\mathrm{h}}$, attributed to the higher intensity of seismic loading. However, with the application of geosynthetics reinforcement, the extent of the developed failure zone is constrained in both the horizontal and vertical directions. The movement of soil 
below footing is hindered by the presence of a high tensile reinforcement to a considerable extent, which consequently reduced the chances of the shear failure of foundation soil beneath the strip footing compared to a footing resting over an unreinforced earth bed.

\section{ADDITIONAL INFORMATION}

b length of the reinforcement layer $(\mathrm{m})$

B width of strip footing (m)

d vertical length of the full wraparound end (m)

$\mathrm{h} \quad$ vertical spacing in between the two consecutive reinforcement layers (m)

$\mathrm{k}_{\mathrm{h}} \quad$ horizontal seismic acceleration coefficient

1 lap length of the reinforcement layer $(\mathrm{m})$

$\mathrm{N}_{\mathrm{c}}$ bearing capacity factor due to the cohesion component of soil

$\mathrm{N}_{\gamma} \quad$ bearing capacity factor from the component of unit weight

$\mathrm{q} \quad$ load-bearing pressure for strip footing resting on an unreinforced earth bed $(\mathrm{kPa})$

$\mathrm{q}_{\mathrm{R}} \quad$ load-bearing pressure for strip footing resting on a reinforced earth bed $(\mathrm{kPa})$

$\mathrm{q}_{\mathrm{u}} \quad$ collapse load per unit width of the footing $(\mathrm{kPa})$

qult ultimate load-bearing capacity for strip footing resting on an unreinforced earth bed $(\mathrm{kPa})$

$\mathrm{qult}_{\mathrm{R}} \mathrm{R}$ ultimate load-bearing capacity for strip footing resting on a reinforced earth bed $(\mathrm{kPa})$

$\mathrm{s} \quad$ settlement of the strip footing $(\mathrm{m})$

$\mathrm{u}$ burial depth of the first layer of reinforcement from the bottom of the footing $(\mathrm{m})$

$\phi \quad$ soil friction angle $\left(^{\circ}\right)$

\section{REFERENCES}

1. Adams, MT and Collin, JG 1997. Large model spread footing load tests on geosynthetic reinforced soil foundations. Journal of Geotechnical and Geoenvironmental Engineering 123(1), 66-72.

2. Akinmusuru, JO and Akinbolade, JA 1981. Stability of loaded footings on reinforced soil. Journal of Geotechnical and Geoenvironmental Engineering 107(6), 819-827.

3. Aria, S, Shukla, SK and Mohyeddin, A 2017. Optimum burial depth of geosynthetic reinforcement within sand bed based on numerical investigation. International Journal of Geotechnical Engineering 14(1), 7179. 
4. Badakhshan, E and Noorzad, A 2017. Effect of footing shape and load eccentricity on behavior of geosynthetic reinforced sand bed. Geotextiles and Geomembranes 45(2), 58-67.

5. Benmebarek, S, Djeridi, S, Benmebarek, N and Belounar, L 2018. Improvement of bearing capacity of strip footing on reinforced sand. International Journal of Geotechnical Engineering 12(6), 537-545.

6. Bera, AK, Ghosh, A and Ghosh, A 2005. Regression model for bearing capacity of a square footing on reinforced pond ash. Geotextiles and Geomembranes 23(3), 261-285.

7. Bolton, MD and Lau, CK 1993. Vertical bearing capacity factors for circular and strip footings on Mohr-Coulomb soil. Canadian Geotechnical Journal 30(6), 1024-1033.

8. Chakraborty, D and Kumar, J 2014. Bearing capacity of strip foundations in reinforced soils. International Journal of Geomechanics 14(1), 45-58.

9. Chugh, AK and Labuz, JF 2011. Numerical simulation of an instrumented cantilever retaining wall. Canadian Geotechnical Journal 48(9), 1303-1313.

10. Fragaszy, RJ and Lawton, E 1984. Bearing capacity of reinforced sand subgrades. Journal of Geotechnical Engineering 110(10), 1500-1507.

11. Guido, VA, Chang, DK and Sweeney, MA 1986. Comparison of geogrid and geotextile reinforced earth slabs. Canadian Geotechnical Journal 23(4), 435440.

12. Huang, CC and Tatsuoka, F 1990. Bearing capacity of reinforced horizontal sandy ground. Geotextiles and Geomembranes 9(1), 51-82.

13. Jaiswal, S and Chauhan, VB 2021. Response of strip footing resting on earth bed reinforced with geotextile with wraparound ends using finite element analysis. Innovative Infrastructure Solutions.

14. Jaiswal, S, Srivastava, A and Chauhan, VB 2020. Numerical Modeling of Soil Nailed Slope Using Drucker-Prager Model. In: Proceedings of Geo-Science and Geo-Structures 2020, Paper ID-GSGS020 Jamshedpur, India.

15. Jaiswal, S, Srivastava, A and Chauhan, VB 2020. Performance of Strip Footing on Sand Bed Reinforced with Multilayer Geotextile with Wraparound Ends. In: Proceedings of Indian Geotechnical Conference 2020, Paper IDTH-10-40, Visakhapatnam, India.

16. Kannaujiya, P and Chauhan, VB 2019. Behavior of Anchored Sheet Pile Wall. In: Shehata H, Brandl H, Bouassida M, Sorour T (eds) Sustainable Thoughts in Ground Improvement and Soil Stability. GeoMEast 2019. Sustainable Civil Infrastructures, 184-195.

17. Kazi, M, Shukla, SK and Habibi, D 2015. An improved method to increase the load-bearing capacity of strip footing resting on geotextile-reinforced sand bed. Indian Geotechnical Journal 45(1), 98-109. 
18. Kazi, M, Shukla, SK and Habibi, D 2015. Behavior of embedded strip footing on sand bed reinforced with multilayer geotextile with wraparound ends. International Journal of Geotechnical Engineering 9(5), 437-452.

19. Kazi, M, Shukla, SK and Habibi, D 2015. Effect of submergence on settlement and bearing capacity of surface strip footing on geotextile-reinforced sand bed. International Journal of Geosynthetics and Ground Engineering 1(1), 4.

20. Kazi, M, Shukla, SK and Habibi, D 2016. Behaviour of an embedded footing on geotextile-reinforced sand. In: Proceedings of the Institution of Civil Engineers-Ground Improvement 169(2), 120-133.

21. Khing, KH, Das, BM, Puri VK, Cook EE and Yen, SC 1993. The bearingcapacity of a strip foundation on geogrid-reinforced sand. Geotextiles and Geomembranes 12(4), 351-361.

22. Kramer, SL 1996. Geotechnical earthquake engineering. India: Pearson Education.

23. Kumar, J and Khatri, VN 2008. Effect of footing roughness on lower bound $\mathrm{N} \gamma$ values. International Journal of Geomechanics 8(3), 176-187.

24. Kumar, P and Chakraborty, M 2020. Seismic Bearing Capacity of Rough Strip Footing Placed Over Geogrid-Reinforced Two-Layer Sands. International Journal of Geomechanics 20(10), 1-12.

25. Lovisa, J, Shukla, SK and Sivakugan, N 2010. Behaviour of prestressed geotextile-reinforced sand bed supporting a loaded circular footing. Geotextiles and Geomembranes 28(1), 23-32.

26. Meyerhof, GG 1963. Some recent research on the bearing capacity of foundations. Canadian Geotechnical Journal 1(1), 16-26.

27. Ojha, R and Chauhan, VB 2019. Performance of Geosynthetic Reinforced Segmental Retaining Walls. In: Shehata H, Brandl H, Bouassida M, Sorour T (eds) Sustainable Thoughts in Ground Improvement and Soil Stability. GeoMEast 2019. Sustainable Civil Infrastructures, 196-206.

28. Omar, MT, Das, BM, Puri, VK and Yen, SC 1993. Ultimate bearing capacity of shallow foundations on sand with geogrid reinforcement. Canadian Geotechnical Journal 30(3), 545-549.

29. OPTUM G2 (2020) Finite Element Program for Geotechnical Analysis, Optum Computational Engineering. www.optumce.com

30. Pandey, A and Chauhan, VB 2019. Numerical Analysis for the Evaluation of Pull-Out Capacity of Helical Anchors in Sand. In: Shehata H, Brandl H, Bouassida M, Sorour T (eds) Sustainable Thoughts in Ground Improvement and Soil Stability. GeoMEast 2019. Sustainable Civil Infrastructures, 207218.

31. Pandey, A and Chauhan, VB 2020. Evaluation of Pull-Out Capacity of Helical Anchors in Clay Using Finite Element Analysis. In: Proceedings of Geo- 
Congress 2020: Modeling, Geomaterials, and Site Characterization, GSP 317, 350-359.

32. Saha, A and Ghosh, S 2019. Modified pseudo-dynamic bearing capacity of shallow strip footing considering fully log-spiral passive zone with global center. Iranian Journal of Science and Technology, Transactions of Civil Engineering 44, 683-693.

33. Shukla, SK 2017. An introduction to geosynthetic engineering. CRC Press.

34. Srivastava, A and Chauhan, VB 2020. Numerical Studies on Two-Tiered MSE Walls Under Seismic Loading. S N Applied Sciences 2(10), 1-7.

35. Srivastava, A, Jaiswal, S and Chauhan, VB 2021. Numerical Study of Geosynthetic-Reinforced Soil Wall Subjected to Static Footing Loading. Proceedings of Engineering and Technology Innovation 17, 13-20.

36. Srivastava, A, Jaiswal, S and Chauhan, VB 2020. The behavior of multi-tiered mechanically stabilized earth (MSE) retaining wall. In: Proceedings of Indian Geotechnical Conference 2020, Paper ID-TH-10-38, Visakhapatnam, India.

37. Terzaghi, K 1944. Theoretical soil mechanics. New York, USA: John Wiley and Sons.

38. Ukritchon, B, Whittle, AJ and Klangvijit, C 2003. Calculations of bearing capacity factor $\mathrm{N} \gamma$ using numerical limit analyses. Journal of Geotechnical and Geoenvironmental Engineering 129(5), 468-474.

39. Yetimoglu, T, Wu, JT and Saglamer, A 1994. Bearing capacity of rectangular footings on geogrid-reinforced sand. Journal of Geotechnical Engineering 120(12), 2083-2099.

Editor received the manuscript: 08.12 .2020 